\title{
Relative research of creative Writing and industries about creative culture
}

\author{
Guangzhi Zhao \\ College of Humanities \& Science \\ Taizhou University \\ Taizhou,Jiangsu,225300 China
}

\begin{abstract}
Creative Writing has been carried out in foreign countries since long time ago, the development has been very mature now, while in our literary education, creative writing is still a vacancy field, genius writers are not trained, but gifted writer needs train. Chinese writing education obvious have shortcomings in our country, the author thinks that we should actively learn effective experience abroad, and manpower to carry out the creative writing, for the development of cultural and creative industries, culture is the foundation of creativity and the core of industrialization direction. Development of cultural and creative industries plays an important role in industrial restructuring and upgrading promoting regional economic development, the use of cultural resources. China's cultural and creative industries in the initial development stages, there are many deficiencies in investment, financing, industrial chain, industrial agglomeration, policy support and human resources development. Finally, the author proposed developed countermeasures in investment and financing, policy support, human resources support and property protection.
\end{abstract}

Keywords- Creative writing, cultural creativity, policy support, protection of property rights

\section{THE NECESSITY OF CREATIVE WRITING}

Chinese people have always been teaching students Practical writing and there is no literature courses in writing, the Department of Chinese students can learn some basic knowledge of writing, but on literary theory of education, students lack of interest which in a way hurt the student's creative desires. Actually, each person is a very good storyteller, humans are born with the original desire of narration and expression, a lot of people have a brilliant dream, but in China, people did not take up the task of cultivating writer, on the contrary, the Department of Chinese students who are forced against the boring literary theory and education, have little writing interest, besides, there is a argument surrounding them: the department of Chinese didn't cultivate writers, their dreams were stranded, teachers feel free to give up discovering and developing talented writers, which resulted in literature tragedy of education, youth writers' dream were strangled in the cradle. Anglo-American literary education is not the same, creative writing has been very mature, most colleges and universities have set up creative writing courses, creative Master the art of writing well-respected education, creative writing, people enjoying life to bring happiness to individuals, written expression becomes smooth and funny to contribute to human literature. mysterious source of the fun lies in creative writing courses at the University of Anglo-American, creative Writing curriculum is set to inspire students, creative interests was looked as the core, the writing was expressed as a kind of entertainment experience things, the form of classroom instruction is flexible, it does not need to be completed in the classroom, people like to call creative writing classes for the studio, they weave together to discuss the story, read their own work in front of everyone, the impact of these practices on raising the level of writing is subtle, these are mutually reinforcing virtuous in AngloSaxon countries, creative writing advocated freedom of expression, when writing break the shackles of the old rules, the creation of a temporary error is allowed, to dispel the concerns of grammar to minimize possible interference in writing so that the text becomes a free expression and interesting process, while in China, the teacher told rule to students and ask students not to violate these prescriptive norms, before their writing, students had to bear a heavy psychological burden on, causing labored expression, and their thought are not smooth, then lost interest in writing. It will be a very effective way to introduce writers to school to promote the development of creative writing. In recent years, China has the case that writers step into a university as professor, Fudan University and Master of creative Writing led the Department of Chinese culture to be the most groundbreaking initiatives, which means China have begun to adopt the advanced educational approach: let writers step into college writing as professor, as China's most international metropolis, Shanghai is the first one to have this advanced ideas and avant-garde practice in the field of writing and also the first one to achieve the international standards, although there are a lot of controversy, but it appears most new things would encounter question, but their vitality will be verified in the near future, and by that time, such a person will be treated as a great landmark for groundbreaking behavior. That writer enter into university to be profess or has many benefits, first of all, writer themselves have a stable job and a good learning and living environment 
for the creation and favorable conditions. Secondly, writer directly guide students and professors writing, in addition to allowing students to get the true mass, but also enable students to successfully close contact with writers, words and deeds, so that students can benefit from it. Actually, in other countries, this has been done for centuries, in China, writers Association assumed the responsibility to cultivate writers, writers lives in a system where the Writers Guild, but in foreign countries, university not only bear the heavy responsibility of cultivating writers, but also bear the heavy responsibility of feeding writers, which not only meets the need of literature development, will also promote the prosperity of literature, the prosperity of Western literature after World War II, can not be divided with the avocations of creative writing and universities training and supporting a successful writer .in 2011 ,Liu Zhen entered into Renmin University of China to act as a profess or, Er Yue, He served as Dean of Zhengzhou University, that many writers were absorbed into the school still lead to heated debate with both positive and negative voices heard, but people who really know literature will realize that, for Chinese literary education , a new era is upon us.

Creative writing is imperative to carry out in China, there has been a pioneer in the country, creative writing light has been shining into the reality of China's literature and clinical education, and it is a very meaningful change, foreign practices worth learning, for this effective educational experience, we should accelerate the introduction of literary. In the future, I believe China will carry out creative Writing Education in many domestic universities like United States, which will be a very gratifying thing. Allow the return of literature Art, in the Department of Chinese people to carry out creative writing school education will bring a promising future for the development of China's literature.

\section{THE DEMARCATION OF CULTURAL AND CREATIVE INDUST RIES}

The current development of cultural and creative industries caused widespread concern, cultural creative industries own cultural, creative and industrial characteris tics, culture and creativity blend with each other, and dependent on certain industrial carrier and the formation of a marketoriented economic value. In practice, there is no unique classification criterion, for example, cultural and creative industries in Shanghai will be divided into five key sectors, including research and development and creative design, architectural design creativity, culture, media and creative, innovative and stylish consumer information and creative planning, involved in national economic statistics in the 38 class industries, 55 small Class industries. Beijing, combined with the development of cultural and creative industries, focus on the direction of the national industry classification in 82 subcategories and six industry sectors, bring them into the scope of cultural and creative industries, including arts and culture, press, publishing, radio and television movies, software, networks and computer services, advertising the exhibition, the art trade, design services, tourism, leisure and entertainment bodies, other ancillary services.
China Creative Industry Research Center of China in the publishing and creative industries in the cultural and creative industries development report is divided into categories of film culture, telecommunications software category, craft fashion, design services category, class performances publishing, consulting and research and educational planning class 8 categories 21 classes, involving 80 national industry categories. Zhejiang Province is divided into the cultural and creative industries and cultural arts, film and television media category, information software category, product design, architectural landscape design, fashion consumer, consulting and planning class 7 categories, 22 in class, involving 76 categories of the national economy industry. The classification above focuses on the reality of local economic and social development, closely linked to the nature of the connotation of cultural and creative industries, reflecting the specific cultural penetration of the industry, reflecting the transformation and upgrading of industrial structure and enhance the quality of people's lives and other aspects. We believe that the creative industries are innovative concept to adapt to the emergence of new forms of industry; cultural industry is the development of new forms of generalization, summary and development. By integrating originalities, creative industries pursue the upgrade of different industries and different areas. This integration break the original boundaries of the second and third industries, it is subsection of upgrading the secondary industry and tertiary industry to promote the creative development of traditional industries, to promote the reform and innovation of social mechanisms. Clearly, on the one hand, cultural and creative industries is a new concept based on cultural industries, on the other hand, the birth and development of creative industries based on manufacturing, growing service industry, it is the results of development of the tertiary industry fusion. Creative industries have content of design, development, manufacturing and other production activities; there are traditional industries in general services, involving more content like art, culture, information, le isure, entertainment and other psychological services activities, it is the new carrier of the urban economy and the development of industrial integration, it is the high-end part of the modern service industry.

\section{CREATIVE WRITING PROMOTES THE DEVELOPMENT OF CULTURAL AND CREATIVE INDUST RIES}

currently, with the deepening of economic globalization, the rapid development of science and technology, culture and economy, the degree of deepening political mutual exchanges, and the more closer combination of science and technology, the increasing economic and cultural content, cultural economy function more highlights, culture has become an important factor in the country's core competitiveness. We should see the to develop cultural and creative industries, is content of comprehensively implementing the scientific concept of development and comprehensive, coordinated and sustainable development, is a strong innovation initiative to enhance the capability of independent innovation and build innovated country, it is a inevitable choice to promote industrial structure upgrading 
and transformation of economic. In the new era, a new condition, creativity has been more than just an academic concept, but has become the promotion of cultural industries with huge economic benefit. Follow the development trend of the times, to further improve the promotion and application of in-depth news publishing industry which represent new digital technology, that promoting press and publishing industry to conduct modern industrial upgrading, has become the industry consensus to seeking to healthy and sustainable development. To this end, we will focus on the following aspects:

\section{A. To develop digital publishing industry and animation industry, and actively participate in international competition}

Accelerating the shift of traditional news publishing industry to a modern content industry, and promoting publishing companies shift to original content and digital publish based on value-added services, realizing content capture, editing, creativity, classification, storage, release, and the whole process of digital transactions. To establish the main criteria to develop the digital publishing industry, improve the scientific and standardized news publishing standardization system. Actively developing the key technologies of digital publishing, promote breakthrough of copyright protection technology, digital printing technology, full Chinese character set technology, high-definition largecapacity optical disc storage technology, electronic paper technology, mobile publishing technology.

\section{B. Vigorously promoting the publication ofmajor projects, and effectively integrating the publishing content resources}

To solve bottleneck of publishing content resources and technology, content integration and digital publishing technology as a starting point, we should innovate publishing workflow, optimize the industrial structure and operating model, improve the level of major publishing projects information and cultural heritage and innovation capability. We should carefully organize and implement to Chinese ceremony compilation and publication projects, Chinese nationals accounted digital book publishing project, the state of knowledge resource database publishing projects, innovative academic publishing project, the revitalization of domestic animation project as the representative of the state's major publishing projects, publishing rich treasure house of resources, enhance China's publishing industry to explore, inherit and carry forward the Chinese nation and the world's ability and level of outstanding culture, the advancement of China's publishing industry in the market structure of world culture. Through the implementation of national key project construction of the Chinese character, national digital publishing complex system development projects, digital copyright protection technology research and development projects, to further promote the development of digital publishing process, improve the level of information the news publishing industry in the new century, occupying the content industry competition initiative and the initiative to lay a solid foundation for China and the Chinese culture to the world publishing.

\section{To improve the institutional environment and actively absorb talents}

Development of cultural and creative industries relies on support of the institutional environment, relies on the talents of leaders and creative work. To fully play the main role in cultural development personnel, it is necessary to form a thick atmosphere of respecting for creativity, innovation and labor, to mobilize the enthusiasm of the news publishing workers, to ensure outstanding original works successfully go toward to market. It is necessary to perfect market and policy environment to the development of cultural and creative entrepreneurial talent, and actively provide good conditions for cultural and creative talents. We need to grasp the publishing market access, product access, and career and job entry access system, standardize the market competition to ensure that the cultural and creative talents can get a reasonable return. It is necessary to actively carry out personnel education, training and technology development, to help publishing and distribution enterprises to be bigger and stronger, to absorb cultural and creative industries talents by industry scale.

\section{REFERENCES}

[1] Hou Bo. Study based on resource industries cultural and creative industries [D]. China University of Geosciences (Beijing), 2009.

[2] Dongxue Bing, Zhu Hui. protection of intellectual property and the development of cultural and creative industries: Models and empirical research [A] School of Economics, Zhejiang University, Institute of Economic Research, Shandong University, "Economic Studies" editorial .2010 year (eighth. ) China Law and Economics Forum Proceedings (Volume) [C], Zhejiang University School of Economics, Institute of Economic Research, Shandong University, "economic Research" Editorial:., 2010:15.

[3] Wang Ruinan. Research Fujian tea culture and creative industry park model built [D]. Fujian Agriculture and Forestry University, 2013.

[4] Suncunxiang. Study Sun Chunxiang fiscal policies. Guangzhou cultural industries [D]. Jinan University, 2013.

[5] Li Yong. Hunan cultural and creative industry competitiveness study [D]. Xiangtan University, 2012.

[6] Yang Jie. Jingdezhen ceramics culture and creative industries risk investment research [D]. Jingdezhen Ceramic Institute, 2013.

[7] Luo Yongmei Chengdu Cultural and Creative Industry Park brand communication strategy research [D]., University of Electronic Science and Technology, 2013. 